Special issue of the 2nd International Conference on Computational and Experimental Science and Engineering (ICCESEN 2015)

\title{
Investigation of the Effects of Moving Targets on Hit Force in Taekwondo
}

\author{
M. Kumartaşli ${ }^{a, *}$, İ.S. ÜnCÜ ${ }^{b}$, F. ÇatikKaş ${ }^{c}$, M. AKYÜZ ${ }^{c}$ And O. Kilim ${ }^{d}$ \\ ${ }^{a}$ Süleyman Demirel University Sport Science Faculty, Sport Science, Isparta, Turkey \\ ${ }^{b}$ Süleyman Demirel University Technology Faculty, Electrical and Electronic Engineering, Isparta, Turkey \\ ${ }^{c}$ Celal Bayar Univesity High School of Physical Education and Sports, Coaching Education, Manisa, Turkey \\ ${ }^{d}$ Süleyman Demirel University Engineering Faculty, Computer Engineering, Isparta, Turkey
}

\begin{abstract}
The system to be developed has been designed in order to determine the training levels of the athletes in the field of taekwondo at national and international level and to follow-up the talent development process using computer support. The progression and continuity of hit power and time-dependent performance improvement of an athlete can be measured with interactive impact measurement system. The system determines a random target. It marks the target by blue light. When the light turns on, the athlete reacts accordingly and swiftly by kicking without knowing the light timing. The athlete only needs to know where the light is. Unlike in other training systems, the piston has been able to go back and forth in response to the strike of the athlete by means of a moving hydraulic system. The athlete can be pushed back by opening the piston when his/her performance drops down. The piston strike model is deactivated when the performance of the athlete is above a given threshold value. There will be four operating phases in the mechanism depending on the impact speed of the piston. Moving target robotic system analyses various hits in Taekwondo with the aim to determine hit force and reaction time. After completion of the warming up at the first stage, the athlete will be able to increase the workout level from low to high levels and will try to keep the mechanism behind as much as possible. Moreover, the athlete will be able to compare his/her results with results of others. Using this system, the efficiency of athletes can be easily determined and deficiencies can be resolved.
\end{abstract}

DOI: 10.12693/APhysPolA.130.382

PACS/topics: 07.05.Rm, 07.07.Mp, 07.10.--h

\section{Introduction}

Systems which increase performance with modern day technology have an important role in success of athletes and help to develop the deficient aspects. The developed system is designed to enable tracking of the capability development process of athletes who work in the field of taekwondo on the national and international level using computer support. Due to this system, the productivity of athletes is determined and deficiencies are pointed out easily. Kicking power continuity and development performances, which depend on timing of athletes' reaction, are measured using a mobile kick measurement system. The system transfers parameters of the kick, that athlete does, to the computer with the aid of load sensors via the USB port. Hydraulic piston is used for seesawing of the system. Movement of the piston is provided with a DC motor.

While the system is returning back, the athlete switches from defense position to attack position in a counter attack. When the system is going forward, the athlete reacts in the defense position.

Taekwondo, besides being an official Olympic sport, is also one of the world's most popular sports among children and adolescents. It is famous for its kicking

\footnotetext{
* corresponding author; e-mail: mehmetkmrtsl@hotmail.com
}

techniques, in which unilateral stance stability is crucial and is a determining factor of success in competitions. In light of the increasing popularity of this sport majority of the practitioners start training at a very young age [1].

In this study computer-based applied-force measurement system is developed. This system defines the force that was applied to moving and stable targets [2].

Due to this study, three area kick skills in main part could be measured using the developed system. these are kick skills against opponent's attack, attacking kick skills when the opponent withdraws and specific kick skills when opponent exactly withdraws. Deficient aspects of the athlete are determined.

\section{Materials and methods}

\subsection{Subjects and sampling}

The subjects of the study include the men's Taekwondo team of the Süleyman Demirel University. There are ten athletes in the team. Representing the ten athletes, three athletes have joined the study. They are also the members of the Turkish National Taekwondo Team.

\subsection{Software part of mobile punch system}

Software interface of the system is given in Fig. 1.

There is a period which is spend on training. Information about target number to which the punch was done, the latest punch information and time remaining 


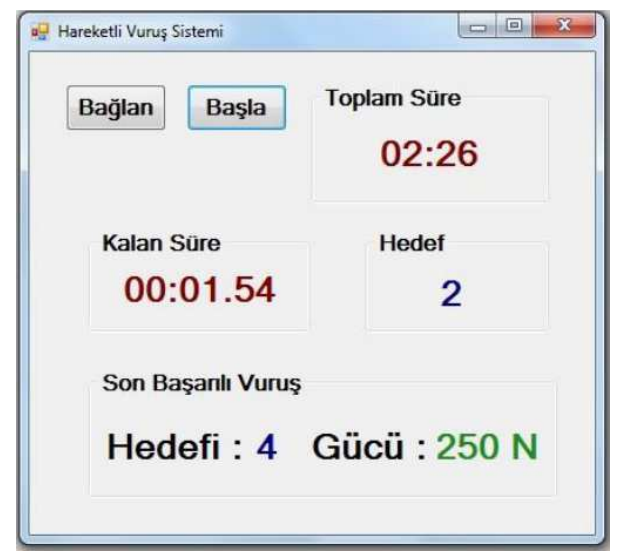

Fig. 1. Interface of mobile punch system.

to strike out the next target are shown in the interface of the system. Training is organized in such way that punches should be done to the target within two minutes. A punch that could not be done within this period is considered as unsuccessful. Punches that are done within this period must pass over a threshold value which is determined in advance. Punches that cannot overpass the threshold value are considered as unsuccessful. There are five load sensors in the system. The numbers that are given for these sensors correspond to target numbers. A sensor number which is selected randomly is transferred to the mechanical system. LED light on the mechanical system shows the target that the athlete has to hit.

\subsection{Hardware part of mobile punch system}

Load sensors are placed at specific points of the created system. Load sensors form a voltage, based on transfer function, under applied force. This signal is amplified using an operational amplifier. Via an analog to digital converter, digital output is obtained proportional to this signal. The obtained digital output is transferred to PC via an interface. Block diagram of the system is given in Fig. 2 [3].

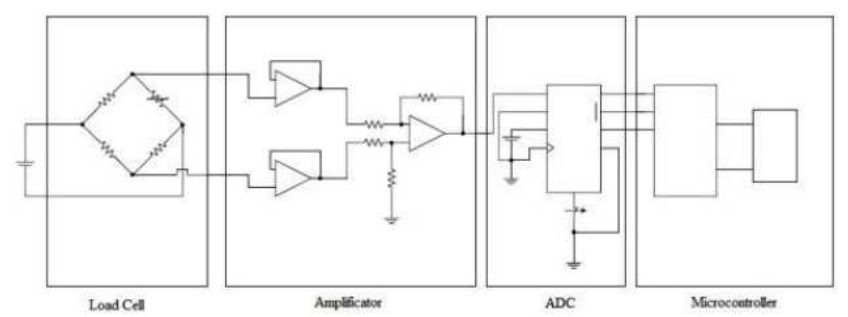

Fig. 2. Block diagram of mobile punch system.

Mechanical part of the system consists of two hydraulic pistons and a DC motor that is used for movement of these pistons. Variable flow of actuators is generally provided with the help of a valve in hydraulic system [4]. This valve provides rocking with the help of DC motor triggered by the software. Moreover, the center of gravity is arranged in such way, as to maintain the momentum during the punch. Mechanical part of the system is shown in Fig. 3.

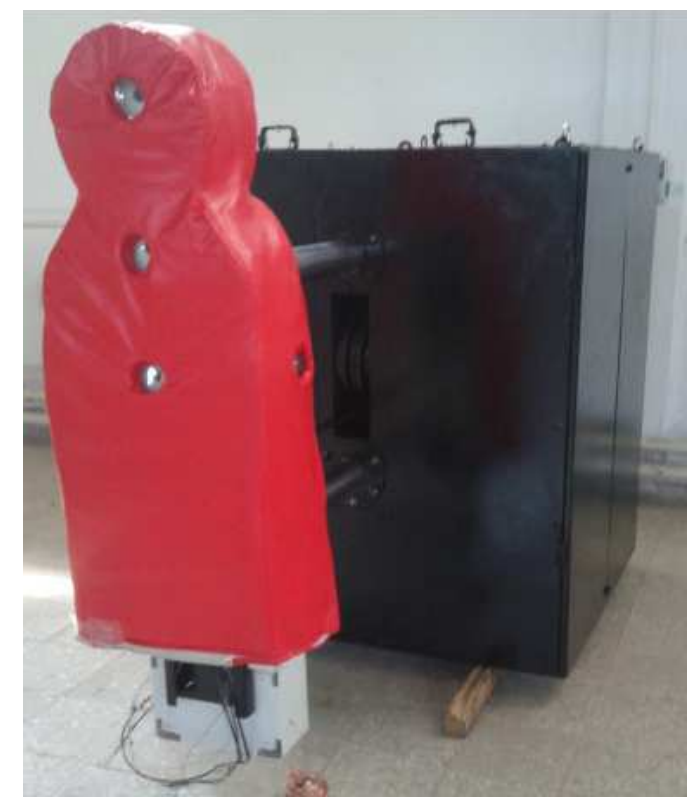

Fig. 3. Mechanics of the system.

\section{Conclusions}

Comparison of athletes can be made by analyzing the plots of data obtained by the system. Deficient aspects of an athlete are revealed by calculating punching power when the opponent of an athlete stands firm and is reciprocating. Kicking power of two athletes is given in Fig. 4, for the case when the opponent is stable.

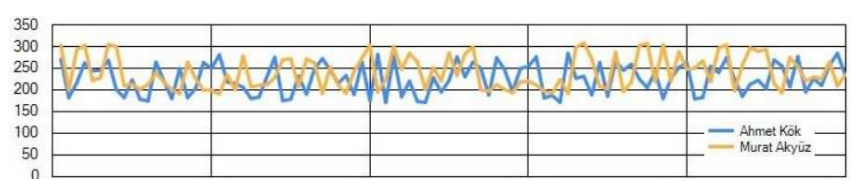

Fig. 4. Comparison of kicking power for a stable opponent.

Attack reactions of two athletes given to advancing opponents are examined in Fig. 5.

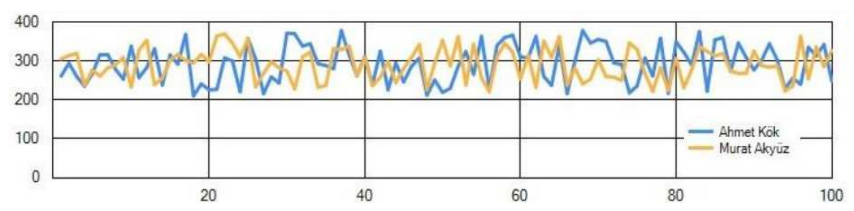

Fig. 5. Comparison of kicking power to advancing opponent.

Attack reaction given by athletes when their opponents were withdrawing is examined in Fig. 6. 


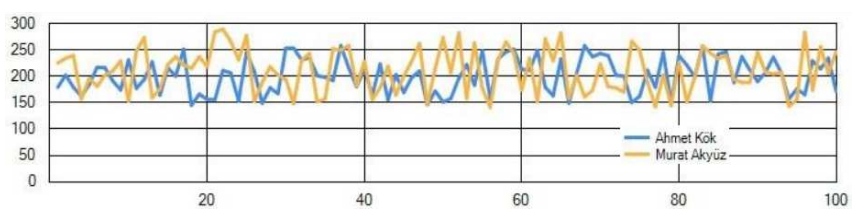

Fig. 6. Comparison of kicking power to retreating opponent.

As a consequence of performed measurements, satisfactory and deficient aspects of athletes are determined. As a result of this study findings athletes can become more successful and more efficient training programs can be organized.

Equipment that provides opportunity for introducing kicking styles into the computer environment and watching both kicking power and punching styles can be created to develop the system.
In addition to the graphs given above, the kick timing on the targets is stable. When the pauses during the kicks increase, the power applied to the target decreases.

The system can be adjusted to the athlete by the adjustment of the height of the training robot.

\section{References}

[1] W. Pieter, in: Combat sports medicine, Eds. R. Kordi, N. Maffulli, R.R. Wroble, S. Wellby, 1st ed., Springer Science, London 2009, ch. 15.

[2] A.S. Prabuwono, H. Akbar, W. Usino, Int. Conf. on Computer Engineering and Technology, Vol. 1, IEEE, Singapore 2009, p. 343.

[3] S. Panthala, N. Islam, S.A. Habib, AU J. Technol. 10, 23 (2006).

[4] S. Tikkanen, M. Vilenius, in: European Control Conference, IEEE, Karlsruhe, Germany 1999 p. 2943. 